\title{
Zdzisław Gębołyś
}

Uniwersytet Kazimierza Wielkiego w Bydgoszczy. Instytut Filozofii

e-mail: zdzislaw.gebolys@ukw.edu.pl

ORCID: 0000-0001-6322-478X

\section{d książki do czy telnika". Międzynarodowa}

\section{Konferencja Naukowa z okazji jubileuszu}

\section{5-lecia Instytutu Informacji Naukowej}

\section{i Bibliotekoznawstwa Uniwersytetu}

\section{Wrocławskiego, 19-20 kw ietnia 2021, Wrocław}

DOI: http://dx.doi.org/10.12775/FT.2021.011

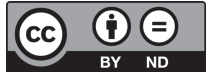

Tekst jest opublikowany na zasadach niewyłącznej licencji Creative Commons Uznanie autorstwa-Bez utworów zależnych 4.0 Międzynarodowe (CC BY-ND 4.0 PL).

Przysłany: 7 VI 2021

Zaakceptowany: 9 VIII 2021

Dr hab. Zdzisław Gębołyś, prof. Uniwersytetu Kazimierza Wielkiego w Bydgoszczy (dalej: UKW) w Instytucie Filozofii UKW. Główne zainteresowania naukowe: zawód bibliotekarza - historia, współczesność, problemy etyki zawodu bibliotekarza; bibliografia - metodyka i teoria; organizacja i zarządzanie w bibliotekach; biblioteki mniejszości polskiej na Litwie i w Republice Czeskiej oraz biblioteki mniejszości niemieckiej w Polsce. Autor ok. 300 publikacji naukowych, m.in. Zawód bibliotekarski na ziemiach niemieckich w latach 1789-1871 (2002); Biblioteki mniejszości niemieckiej w II Rzeczypospolitej (2012). Współredaktor pierwszej na świecie kompletnej antologii narodowych kodeksów etyki bibliotekarskiej (2008), 2012 - wersja anglojęzyczna. Tłumacz i redaktor wydania krytycznego Katechizmu biblioteki Paula Ladewiga (2016) na język polski, angielski i słowacki. Autor kilku bibliografii, w tym: Bibliografia druków w języku polskim wydanych na Litwie od 1944 do 2014 roku (2015). Redaktor Kroniki w „Przeglądzie Bibliotecznym” (2005-2009). Członek wielu stowarzyszeń zawodowych i naukowych, polskich i zagranicznych. Stypendysta niemieckich fundacji. Udział w konferencjach, wyjazdach studyjnych, wyjazdach naukowych i dydaktycznych w ramach programu Erasmus. Członek polsko-niemiecko-czeskiego Zespołu Bibliografii Historii Śląska (1987- ), członek zespołu Stowarzyszenia Bibliotekarzy Polskich ds. opracowania kodeksu etyki zawodowej bibliotekarza i pracownika informacji (2005).

treszczenie: W dniach 19-20 kwietnia 2021 r. we Wrocławiu miała miejsce międzynarodowa konferencja naukowa dla uczczenia jubileuszu 65-lecia utworzenia na Uniwersytecie Wrocławskim akademickiego ośrodka kształcenia bibliotekarzy na poziomie wyższym, którego chlubne tradycje kontynuuje dziś Instytut Informacji Naukowej i Bibliotekoznawstwa. 
W sprawozdaniu z tego wydarzenia zawarto charakterystykę imprezy. Omówiono poszczególne wystąpienia konferencyjne, zestawiając je w wyróżniające się pod względem treściowym bloki tematyczne: czytelnictwo; edytorstwo; źródła informacji o książce; biblioteki; nauka o książce; ruch wydawniczy. Zwrócono uwagę na podstawowe hipotezy i tezy badawcze zawarte w referatach. $W$ omówieniu referatów zagranicznych zaakcentowane zostały obecne w nich polonica. Podkreślona została sprawność organizatora, który wskutek pandemii COVID-19 zmuszony był do przeprowadzenia konferencji w trybie zdalnym. Wyzyskał w pełni wszystkie możliwości, jakie daje ta formuła, a zwłaszcza czat, dzięki czemu możliwe było komentowanie na gorąco prezentowanych referatów, zadawanie pytań referentom oraz wymiana poglądów pomiędzy uczestnikami. Warto też zaznaczyć, że konferencji towarzyszyła międzynarodowa wystawa ekslibrisu pod hasłem wywoławczym: „Instytut Informacji Naukowej i Bibliotekoznawstwa Uniwersytetu Wrocławskiego".

łowa kluczowe: sprawozdanie; bibliologia i informatologia

W dniach 19-20 kwietnia 2021 r. miała miejsce jubileuszowa konferencja Instytutu Informacji Naukowej i Bibliotekoznawstwa Uniwersytetu Wrocławskiego (dalej: UWr). Wrocławski ośrodek bibliologiczny, jeden z najstarszych w Polsce, od lat zagląda do kalendarza, podkreśla okrągłe i „półokrągłe” daty wyznaczające kolejny etap nieprzerwanej od 1956 r. działalności i wykorzystuje je jako okazję do świętowania. Chlubna ta i godna naśladowania tradycja. Nie zmąciła jej nawet siejąca powszechny zamęt pandemia COVID-19. Zmusiła wprawdzie organizatorów do zmiany formuły konferencji, ale nie zniechęciła do godnego uczczenia jubileuszu.

Członkowie i przyjaciele wrocławskiej bibliologicznej wspólnoty nie spotkali się jak zwykle w gościnnych murach przy placu Uniwersyteckim 9/13, tym razem nie w „realu”, a w „wirtualu”. Formuła zdalnej konferencji, wymuszona co prawda, nie przeszkodziła bynajmniej w jej zorganizowaniu i w przeprowadzeniu.

Nieco statystyk na początek. Dwudniowa konferencja została podzielona na osiem sesji, każda z nich była wypełniona przez cztery referaty. Autorami 32 referatów było 35 prelegentów (dwa wystąpienia przygotowały pary autorskie). Konferencja wrocławska jak najbardziej zasługuje na określenie międzynarodowa, zarówno w ujęciu podmiotowym, jak i przedmiotowym. Na 32 referaty aż 15 zostało przygotowanych przez zagranicznych gości. Polską bibliologię reprezentowało 16 referatów, a jeden został przygotowany przez polsko-ukraińską parę autorską. Po przejrzeniu bardzo starannie przygotowanych konferencyjnych materiałów informacyjnych skonstatowaliśmy, że owa polsko-zagraniczna równowaga była jednym z założeń konferencji. Organizatorzy, jak sądzimy, nie mniejszych starań dołożyli, aby dobór uczestników oraz tematy wystąpień odpowiadały randze wydarzenia. Z Polski „zjechało” na konferencję 17 osób, w tym z największych ośrodków akademickich. Najliczniejszą reprezentację wystawili, co jest już tradycją i dobrym zwyczajem, gospodarze. „Drużyna” UWr, będąca połączeniem doświadczenia i młodości, liczyła 10 osób. Polski obóz współtworzyli referenci z: Uniwersytetu Warszawskiego (dalej: UW), Uniwersytetu Śląskiego (dalej: UŚ), Uniwersytetu Jagiellońskiego (dalej: UJ), Katolickiego Uniwersytetu Lubelskiego (dalej: KUL), 
Uniwersytetu Marii Curie-Skłodowskiej w Lublinie (dalej: UMCS), Uniwersytetu Mikołaja Kopernika w Toruniu (dalej: UMK), Uniwersytetu Gdańskiego (dalej: UG), Uniwersytet Łódzkiego (dalej: UŁ), Krakowskiej Akademii im. A. Frycza Modrzewskiego (dalej: KAFM) oraz Zakładu Narodowego im. Ossolińskich we Wrocławiu (dalej: ZNOW). Z zagranicy „przybyło” do Wrocławia 16 gości, największa liczba (7 osób) z zaprzyjaźnionego z Wrocławiem Lwowskiego Uniwersytetu Narodowego im. Iwana Franki (dalej: LUN). Po dwóch referentów zawitało z Katolickiego Uniwersytetu im. Pétera Pázmánya w Budapeszcie (dalej: KUB) oraz Uniwersytetu Jana Komeńskiego w Bratysławie (dalej: UJKB). W gronie uczestników znalazły się pojedyncze osoby z Austrii (Rüdiger Wischenbart Content \& Consulting, dalej: RWCC), Słowenii (Uniwersytet w Lublanie, dalej: UL), Czech (Muzeum Narodowe w Pradze, dalej: MNP) Litwy (Uniwersytet Wileński, dalej: UWil) i Finlandii (Uniwersytet w Helsinkach, dalej: UH).

Mottem konferencji, wyrażonym w lapidarnym tytule „Od książki do czytelnika”, były właśnie te dwa słowa (książka i czytelnik), które są niejako symbolami funkcjonowania książki. Refleksja nad życiem książki, dawniej i współcześnie. Taki ogólny cel przyświecał właśnie organizatorom. Aby nadać konferencji wymiar jak najbardziej powszechny, a co najmniej europejski, zaproszeni zostali do rozważań nad złożonymi relacjami zachodzącymi pomiędzy książką a czytelnikiem badacze z różnych krajów i z różnych środowisk akademickich.

Konferencje jubileuszowe z reguły nie mają charakteru monotematycznego. Najczęściej pod względem treści odznaczają się różnorodnością podporządkowaną motywowi przewodniemu, nakreślonemu przez organizatorów zwykle w tytule konferencji. Tak też było i w tym przypadku. W swoistym silva rerum, którym jest zbiór referatów konferencyjnych, da się wyróżnić kilka wyraźnych bloków tematycznych ${ }^{1}$. Na czoło pod względem ilościowym wysuwają się trzy bloki: Czytelnictwo (9); Źródła informacji o książce (9) oraz Edytorstwo (6). Pozostałe referaty przydzieliliśmy do trzech mniejszych grup: Biblioteki (3); Nauka o książce (4); Ruch wydawniczy (3). W takim też porządku pragniemy je pokrótce przedstawić i omówić.

Zagadnienie czytelnictwa w różnych kontekstach, językach, środowiskach geograficznych oraz rodzajach i gatunkach literackich były treścią aż dziewięciu referatów. Zacznijmy od perspektywy geograficznej. Aleksander Bednarski (KUL) omówił wizualne wyznaczniki współczesnej powieści walijskiej, w szczególności ekfrazy, elementy piktorialne, ilustracje oraz okładki. Danuta Stanulewicz (UG) przedstawiła stan współczesnej literatury dla dzieci i młodzieży tworzonej w języku kaszubskim, nakreślając w tle problemy związane z czytelnictwem tej literatury. W realia XVIII-wiecznej Finlandii przeniosła słuchaczy Tuija Lainego (UH), pokazując na przykładzie literatury religijnej dysonans występujący pomiędzy umiejętnością czytania a nie zawsze z nią korespondującą zdolnością rozumienia czytanych tekstów. Ze sporym zainteresowaniem spotkały się dwa referaty z tego kręgu, przygotowane przez gości z Węgier, między innymi z uwagi na polskie akcenty.

Od książki do czytelnika. Międzynarodowa Konferencja Naukowa z okazji Jubileuszu 65-lecia Instytutu Informacji Naukowej i Bibliotekoznawstwa Uniwersytetu Wroclawskiego. Abstrakty = The Book and the Reader. International Jubilee Conference on the 65 th anniversary of the Institute of Information and Library Science of Wrocław. Abstracts, red. A. Cisło, K. Augustyn, D. Stanulewicz. R. Werszler, Wrocław 2021. 
Lajos Pálfalvi (KUB) dokonał „egzegezy” antypolskiej propagandy w węgierskiej powieści dla młodzieży, biorąc na warsztat powieść Istvána Petrovacsa pt. „Dziewczyna z Wiktorskiej" jako przykład dzieła obliczonego na rozbudzenie antypolskich resentymentów na bazie ideologicznej. Anna Tomoriné Szesztay (KUB) omówiła mechanizmy działania węgierskiej cenzury prewencyjnej wobec dzieła Henryka Sienkiewicza pt. „W pustyni i w puszczy”. Przedmiotem swojego referatu Mariola Antczak (UŁ) uczyniła zagadnienia odbioru przez polskich badaczy książek amerykańskiej psycholog Jean Twenge. Według referentki obserwacje J. Twenge dotyczące zachowań amerykańskich nastolatków można dostrzec również u polskich rówieśników, a w nich szukać przyczyn spadku zainteresowania młodego pokolenia czytaniem książek.

Polski wymiar czytelnictwa odnaleźć można w trzech referatach. Bożena Koredczuk (UWr) podjęła słabo dotąd rozpoznany w Polsce problem tak zwanej biografii lekturowej, wpływu lektur na wizję świata, na poglądy, a także na relacje międzyludzkie. Wpływ pandemii na czytelnictwo w Polsce znalazł odbicie w dwóch referatach. Anna Dymmel (UMCS) zajęła się nurtującym nas wszystkich problemem wpływu pandemii na praktyki czytelnicze młodego pokolenia. Krótki dystans dzielący autorkę od badanego problemu każe postawić wobec rezultatów podjętych badań znak zapytania, nie kwestionując wszak postawionych w referacie hipotez dotyczących zmian zachowań czytelniczych, a zwłaszcza przyczyn tych zmian. Agnieszka Łuszpak (UWr) przeanalizowała doniesienia w mediach na temat medialnego obrazu czytelnictwa. Zebrane wypowiedzi poddano analizie ilościowej i jakościowej, pokazując na tej podstawie najczęściej poruszane w mediach tematy.

Edytorstwo książki znalazło rezonans w sześciu referatach. Forma materialna książki to sam w sobie interesujący materiał badawczy. To przyczynek do wieloaspektowych rozważań na temat estetyki książki, upodobań czytelniczych, mecenatu, a nawet recepcji. Co mówi okładka książki, pyta w podtytule swojego referatu zgoła retorycznie Anna Cisło (UWr), i odpowiada na nie z perspektywy semiotycznej, widząc w okładce źródło tożsamości lekturowej, zachętę do lektury książki, a niejednokrotnie impuls do odkrywania rzeczywistości pozalekturowej. Marcin Cziomer (KAFM), grafik i wykładowca akademicki, omówił przykłady realizacji wizualnych stosowanych we współczesnej książce (ilustracje, okładki, ekslibrisy), stawiając otwarte pytanie o rolę ilustracji (elementów wizualnych), o balans pomiędzy formą a treścią książki.

O tym, jak wiele można wyczytać z dedykacji, przekonała słuchaczy Anna Gruca (UJ). Analizując drukowane dedykacje z XIX-wiecznych książek, przedstawiła ich nadawców i adresatów, zwróciła również uwagę na pojawiające się w dedykacjach elementy zachęty do zakupu. Ukraiński badacz, Mykola Ilkiv-Svydnytskyi (LUN), zajął się wpisami własnościowymi (autografami i ekslibrisami) Jana Dantyszka w książce pochodzącej z biblioteki uczonego, w edycji Sylw Stacjusza wydanej w Wenecji w 1502 r. Richard Šipek (MNP) zainteresował się zapiskami Matthiasa Stoiusa, profesora medycyny z Królewca, zamieszczonymi w Almanachu, jednym z 55 tomów dzieła Bibliotheca Nostica. Zapiski Stoiusa to ważny przyczynek wiedzy 
nie tylko o autorze, ale również o jego rodzinie, o pruskiej rodzinie książęcej, o zainteresowaniach czytelniczych autora tego dzieła.

Jolanta Gwioździk (UŚ) przyjrzała się w swym referacie formom i funkcjom książki współczesnej. Przypomniała, czym była dotąd książka: jednym uświadomiła, innym przypomniała to, czego jesteśmy świadkami, a w zasadzie uczestnikami, że książka podlega ciągłym przeobrażeniom, że staje się w coraz większym stopniu interaktywnym medium wymagającym udziału czytelnika.

Jak dotrzeć do odpowiednich książek w powodzi informacji, jakich szukać pomocy, programów, wydawnictw? Odpowiedzi na te pytania próbowała udzielić grupa referentów z Polski i zagranicy w cyklu referatów poświęconych źródłom informacji o książce. Małgorzata Góralska (UWr) zainteresowała się technologiami służącymi do skutecznego wykrywania i rekomendowania książek dostępnych w Internecie. W tym kontekście wskazała wybrane mechanizmy umożliwiające skuteczną ekspozycję książek w sieci oraz zapewniające czytelnikom dostęp do spersonalizowanej oferty tytułowej.

Elżbieta Jabłońska-Stefanowicz (UWr) poświęciła swój referat filtrom różnego rodzaju (osoby, wydawcy, wydawnicze programy komputerowe), które służą czytelnikowi do rozpoznawania stale rosnącej oferty wydawniczej, czasami paradoksalnie przeszkadzającej w tym procesie.

Polsko-ukraińska para referentów, Roman Krochmalny (LUN) i Halina Rusińska-Giertych (UWr), zajęła się rolą książki w procesie dydaktycznym uczelni. Na podstawie badań ankietowych studentów UWr i LUN podjęli oni próbę zidentyfikowania znaczenia książki jako źródła informacji edukacyjnej, zarówno na nośnikach tradycyjnych, jak też elektronicznych.

Źródłem wiedzy, wcale nie gorszym, mogą być dokumenty pochodne oraz prymarne. Lesia Kupyn (LUN) zaprezentowała wyniki eksploracji kartoteki „Kwartalnika Historycznego" z lat 1935-1939, znajdującej się w Bibliotece Naukowej Uniwersytetu Lwowskiego. Ilona Oleksiw (LUN) przedstawiła wyniki kwerendy archiwalnej dotyczącej informacji odnośnie do Towarzystwa Miłośników Książki we Lwowie (1925-1939) znajdujących się w Dziale Rękopisów Lwowskiej Narodowej Biblioteki Naukowej im. Stefanyka. Zachowane kwity, korespondencja, rachunki, sprawozdania dają wyobrażenie o działalności towarzystwa w tym okresie i jego roli w życiu naukowym i kulturalnym Lwowa.

Kamila Augustyn (UWr) zajęła się rolą źródeł informacji w kształtowaniu studiów z zakresu rynku wydawniczego na poziomie akademickim. Zwróciła uwagę na konieczność interdyscyplinarnego spojrzenia na produkcję i obieg wydawanych publikacji, zaapelowała o reorientację badań nad rynkiem wydawniczym poprzez uwzględnianie w programach studiów dzieł z obszaru kultury i edukacji, ale również ze świata biznesu.

W nurt rozważań historycznych nad źródłami wiedzy wpisuje się również referat Rafała Werszlera (UWr) poświęcony francuskiemu modelowi systemu wiedzy Jeana Garniera, który został wykorzystany przez rektora szkoły w Kłodzku, Joanne'a Millera, do porządkowania zasobów archiwów w hrabstwie kłodzkim. Temu 

f́lia temat podręczników języka polskiego w Akademii Jezuickiej we Lwowie w XVIItoru $\quad-X V I I I$ w. Referent nie ograniczył się do charakterystyki podręczników. Przedstawił niensia je jako jeden z elementów przeobrażeń w sferze kultury i języka, zmagania tradycji ze współczesnością, ustępowania łaciny na rzecz języka polskiego w podręcznikach i programach Iwowskiej szkoły.

W założenia konferencji wpisuje się grupa trzech referatów dotyczących problemów upowszechniania książki. Anna Lubińska (UWr) sięgnęła w związku z tym po dwie książki Umberto Eco: „Wahadło Foucault” i „Na każdy temat”, pokazując na ich przykładzie problemy i dylematy związane z pracą redaktora wydawniczego, zwłaszcza w relacjach z autorem.

Aušra Navickienė (UWil) skierowała uwagę słuchaczy w stronę historii ruchu wydawniczego. O firmie wydawniczej Józefa Zawadzkiego wiemy już bardzo wiele z wcześniejszych opracowań, ale na pewno nie wszystko. Tym dotąd nieodkrytym bądź słabo rozpoznanym wątkiem było wydawanie przez Zawadzkiego książek w języku litewskim w latach 1805-1864.

Dystrybucji wydawnictw stowarzyszenia Hałycko-Ruska Matycia, założonego w 1848 r., przyjrzał się Oleksandr Sedliar (LUN). Upowszechnianiem tanich książek dla ludu zajmowały się instytucje (Instytut Stauropigialny), księgarnie oraz księża greckokatoliccy. Zważywszy na ograniczenia komunikacyjne i nie mniej istotne edukacyjne (duży poziom analfabetyzmu), wysiłki te nie odnosiły oczekiwanych skutków, gdyż książki nie docierały do większości ruskich chłopów.

$\mathrm{Na}$ konferencji bibliologicznej nie mogło zabraknąć referatów o bibliotekach. Małgorzata Fedorowicz-Kruszewska (UMK) przedstawiła w swoim referacie koncepcję biblioteki ekologicznej jako odpowiedź na wzrastającą rolę biblioteki w upowszechnianiu wiedzy na temat środowiska naturalnego. Referentka dokonała redefinicji terminu „ekologiczna biblioteka”. Poprzez eksplorację bibliograficznej bazy danych LISTA zebrała literaturę na ten temat, wykorzystując ją następnie do określenia wskaźników ekologicznej biblioteki.

Bibliotekom Wrocławia, działającym w latach 1945-1953, poświęciła swój referat Maria Pękalska (ZNOW), pokazując ich rolę w życiu mieszkańców polskiego Wrocławia, podnoszących miasto z wojennych gruzów, ale też na dowód tezy, że „nie samym chlebem człowiek żyje”, szukających w książkach azylu, a może i ukojenia w tych trudnych czasach.

Słowackie badaczki, Marta Špániová i Lucia Lichnerová (UJKB), omówiły zasoby bibliotek jezuickich w Królestwie Węgier w XVIII w., w szczególności zwracając uwagę na wydane przez jezuitów książki budzące uznanie także poza Węgrami, czego przykładem mogą być przekłady wielu z nich na język polski.

Dobrze się stało, że w programie konferencji znalazły się również referaty przenoszące płaszczyznę dyskusji na poziom ogólniejszy. Wprawdzie przykłady są pouczające, ale też dla ich omówienia potrzebna jest refleksja na temat natury i przedmiotu badań. $W$ tę stronę skierowały słuchaczy cztery referaty. Jadwiga 
Woźniak-Kasperek (UW) zapoznała nas z praktycznymi skutkami reformy szkolnictwa wyższego (2018), w wyniku której bibliologia i informatologia z pozycji samodzielnej dyscypliny badawczej, w ramach tak zwanej konsolidacji, została sprowadzona do pozycji subdyscypliny wchodzącej w zakres nauki o komunikacji społecznej i mediach oraz nauk o poznaniu i komunikacji społecznej.

Miha Kovač ze Słowenii (UL) nieco prowokacyjnie wystąpił z tezą, że nauka o książce to dyscyplina naukowa bez przedmiotu badań. Dzieje się tak, jego zdaniem, za sprawą zmienności formy książki, jej funkcji społecznej i kulturowej.

Natalia Demczuk (LUN) przybliżyła zapomnianą, przynajmniej w Polsce, a w okresie międzywojennym obecną u nas postać ukraińskiego badacza Dymitra Bałyki. D. Bałyka reprezentował w nauce o książce nurt bibliopedagogiczny. Referentka omówiła jego najważniejsze osiągnięcia organizacyjne (Gabinet Badania Książki i Czytelnictwa w Kijowie) oraz osiągnięcia naukowe (dzieła, ankiety).

Rüdiger Wischenbart z Austrii (RWCC) pokusił się w swoim referacie o charakterze teoretyczno-praktycznym o udowodnienie hipotezy badawczej określonej w tytule, a mówiącej o tym, jak czytanie książki stało się czymś zupełnie innym. Referent zwrócił uwagę na coraz powszechniejszy zanik samotności czytelniczej na rzecz kontaktu czytelnika z autorami, wydawcami, dystrybutorami książek. Rozmowę o książkach wzbogacają też niewątpliwie media społecznościowe.

Ozdobą każdej konferencji są kuluary. Niestety w konferencjach przeprowadzanych w trybie online jako takie nie istnieją, chyba że za ich namiastkę uznać czat dający możliwość zamieszczania „gorących” komentarzy przez uczestników. Konferencjom towarzyszą często tak zwane imprezy towarzyszące o charakterze promocyjnym, czasami też artystycznym. Za taką imprezę, zarazem świetny pomysł organizatorów, należy uznać wystawę towarzyszącą konferencji pt. „Ekslibris Instytutu Informacji Naukowej i Bibliotekoznawstwa Uniwersytetu Wrocławskiego". Do udziału w wystawie zostali zaproszeni twórcy z całego świata. Ogółem wpłynęły prace 32 grafików z ośmiu krajów (Czechy, Kazachstan, Meksyk, Norwegia, Polska, Rosja, Serbia, Ukraina). Głównym motywem prezentowanych ekslibrisów była książka oraz sam Jubilat. Podczas konferencji miał miejsce wernisaż wystawy².

Zarówno w trakcie konferencji, jak i na jej zakończenie, nie zabrakło życzeń składanych Instytutowi, gratulacji z powodu bardzo udanej i stojącej na wysokim poziomie konferencji, a także życzeń dalszych osiągnięć, sukcesów naukowych i dydaktycznych. Dołączamy się do nich z tradycyjnym Ad multos annos! i z nadzieją, że już wkrótce, z okazji 70-lecia Instytutu, spotkamy się ponownie.

\footnotetext{
Z okazji wystawy zostal wydrukowany dwujęzyczny, polsko-angielski okolicznościowy katalog - zob. Ekslibris Instytutu Informacji Naukowej i Bibliotekoznawstwa. Wystawa towarzysząca Międzynarodowej Konferencji Naukowej „Od książki do czytelnika" = Bookplates of the Institute of Inforation and Library Science of the University of Wroclaw. The exhibition accompanying the International Jubilee Conference "The book and the Reader, red. R. Werszler, A. Cisło, K. Augustyn, Wrocław 2021.
} 


\section{Bibliografia}

Werszler, Rafał, Anna Cislo, i Kamila Augustyn, red. 2021. Ekslibris Instytutu Informacji Naukowej i Bibliotekoznawstwa. Wystawa towarzysząca Międzynarodowej Konferencji Naukowej „Od książki do czytelnika” = Bookplates of the Institute of Inforation and Library Science of the University of Wroclaw. The exhibition accompanying the International Jubilee Conference "The book and the Reader. Wrocław: Wydawnictwo Uniwersytetu Wrocławskiego.

Cisło, Anna, Kamila Augustyn, Danuta Stanulewicz, i Rafał Werszler, red. 2021. Od książki do czytelnika. Międzynarodowa Konferencja Naukowa z okazji Jubileuszu 65-lecia Instytutu Informacji Naukowej i Bibliotekoznawstwa Uniwersytetu Wroclawskiego. Abstrakty = The Book and the Reader. International Jubilee Conference on the 65 th anniversary of the Institute of Information and Library Science of Wrocław. Abstracts. Wrocław: Wydawnictwo Uniwersytetu Wrocławskiego. 


\section{Zdzisław Gębołyś}

Kazimierz Wielki University in Bydgoszcz. Institute of Philosophy

e-mail: zdzislaw.gebolys@ukw.edu.pl

ORCID: 0000-0001-6322-478X

\section{"From the book to the reader." International}

\section{Scientific Conference on the occasion of the}

\section{5th anniversary of the Institute of Library}

\section{and Information Science at the University of}

\section{Wrocław, 19-20 April 2021, Wrocław}

DOI: http://dx.doi.org/10.12775/FT.2021.011

(c) $\bigodot_{\mathrm{BY}} \bigodot_{\mathrm{ND}}$ The text is available under a Creative Commons Attribution-NoDerivatives 4.0
International (CC BY-ND 4.0).

Received: 7 VI 2021

Accepted: 9 VIII 2021

Doctor habilitatus Zdzisław Gębołyś, professor at the Kazimierz Wielki University in Bydgoszcz (hereinafter: UKW) at the Institute of Philosophy of UKW. His main scientific interests include: the profession of a librarian - history, present, problems of ethics of the librarian's profession; bibliography - methodology and theory; organization and management in libraries; libraries of the Polish minority in Lithuania and the Czech Republic, and libraries of the German minority in Poland. He is an author of about 300 scientific publications, among others, The librarian profession in Germany in the years 1789-1871 (2002); Libraries of the German minority in the Second Polish Republic (2012). Co-editor of the world's first complete anthology of national codes of librarian ethics (2008), 2012 - English version. Translator and editor of the critical edition of Paul Ladewig's Catechism of the Library (2016) into Polish, English, and Slovak. Author of several bibliographies, including: Bibliography of prints in Polish published in Lithuania from 1944 to 2014 (2015). The editor of the Chronicle in "Przegląd Biblioteczny" (2005-2009). Member of many professional and scientific associations, both Polish and foreign. Scholarship holder of German foundations. Participated in conferences, study trips, scientific and didactic trips under the Erasmus program. Member of the Polish-German-Czech Bibliography Team of the History of Silesia (1987-), member of the team of the Association of Polish Librarians for the development of the code of professional ethics of the librarian and information worker (2005).

eywords: report; bibliology and informatology 
A bstract: On April 19-20, 2021, an international scientific conference was held in Wrocław to celebrate the 65th anniversary of the establishment of an academic centre for the education of librarians at the University of Wrocław at the higher level, whose estimable traditions are folia continued today by the Institute of Library and Information Science. The report on this event for $u$ contains the characteristics of the event. Individual conference speeches were discussed, niensia juxtaposing them in thematic blocks in terms of contents: readership; editing; sources of information about a book; libraries; bibliology; publishing traffic. Attention was paid to the basic hypotheses and research theses contained in the papers. In the discussion of foreign papers, the polonica present in them were emphasized. The efficiency of the organizer was highlighted, who, as a result of the COVID-19 pandemic, was forced to conduct the conference remotely. He took full advantage of all the possibilities offered by this formula, especially of the chat, thanks to which it was possible to comment on the presented papers, ask questions to the speakers and exchange views between the participants. It is also worth noting that the conference was accompanied by an international exhibition of ex libris under the slogan: "Institute of Library and Information Science of the University of Wrocław." 


\section{Zdzisław Gębołyś}

Kazimierz Wielki Universität in Bydgoszcz (Bromberg). Institut für Philosophie E-Mail: zdzislaw.gebolys@ukw.edu.pl

ORCID: 0000-0001-6322-478X

\section{Vom Buch zum Leser. Die Internationale}

\section{Wissenschaftliche Tagung anlässlich des 65.}

\section{Jubiläums des Instituts für Wissenschaftliche}

\section{Information und Bibliotheksw issenschaft}

\section{der Universität Wrocław (Breslau),}

\section{9.-20. April 2021}

DOI: http://dx.doi.org/10.12775/FT.2021.010 (c) $\bigodot_{\mathrm{BY}}$
Bearbeitungen 4.0 International (CC BY-ND 4.0) veröffentlicht.

Zugesandt: 7 VI 2021

Angenommen: 9 VIII 2021

Dr. habil. Zdzisław Gębołyś, Professor der Kazimierz Wielki Universität in Bydgoszcz (Bromberg) (weiter im Text als KWU) am Institut für Philosophie der KWU. Das Hauptforschungsinteresse: der Beruf des Bibliothekars - Geschichte, Gegenwart, Probleme der Berufsethik des Bibliothekars, die Bibliografie - Methodik und Theorie, die Organisation und Verwaltung in den Bibliotheken, die Bibliotheken der polnischen Minderheit in Litauen und der Tschechischen Republik sowie die Bibliotheken der deutschen Minderheit in Polen. Autor von ca. 300 wissenschaftlichen Publikationen, u.a. Zawód bibliotekarski na ziemiach niemieckich w latach 1789-1871 [Der Beruf des Bibliothekars auf den deutschen Gebieten in den Jahren 1789-1871] (2002); Biblioteki mniejszości niemieckiej w II Rzeczypospolitej [Bibliotheken der deutschen Minderheit in der Zweiten Republik Polen] (2012). Mitredakteur der weltweit ersten ausführlichen Anthologie von nationalen Kodizes der Bibliothekarsethik (2008), 2012 - in englischer Fassung. Übersetzer und Redakteur der kritischen Ausgabe vom Katechismus der Bibliothek Paul Ladewigs (2016) in der polnischen, englischen und slowakischen Sprache. Autor von einigen Bibliografien, darunter: Bibliografia druków w języku polskim wydanych na Litwie od 1944 do 2014 roku [Bibliografie der in Litauen herausgegebenen polnischen Drucke seit 1944 bis 2014] (2015). Redakteur des Chronikteils der Zeitschrift "Przegląd Biblioteczny“ (2005-2009). Mitglied zahlreicher Berufsverbände sowohl in Polen als auch außerhalb der polnischen Grenzen. Stipendiat deutscher Stiftungen. Teilnehmer von Tagungen, Studien-, Forschungs- und Lehrreisen im Rahmen des Erasmus-Programms. Mitglied des polnischdeutsch-tschechischen Teams zur Bearbeitung der Bibliografie zur Geschichte Schlesiens 
(1987-), des Teams des Verbands der polnischen Bibliothekare zur Bearbeitung des Kodex der Berufsethik des Bibliothekars und Informationsmitarbeiters (2005).

tichworte: Bericht; Bibliologie und Informatologie

usammenfassung: Am 19.-20. April 2021 fand in Wrocław (Breslau) eine internationale wissenschaftliche Tagung anlässlich des 65. Jubiläums der Entstehung eines akademischen Zentrums für bibliothekarische Hochschulbildung an der Universität Breslau statt, dessen Tradition heutzutage das Institut für Wissenschaftliche Information und Bibliothekswissenschaft fortsetzt. Im Bericht über dieses Ereignis knüpfte man an die Charakteristik des Ereignisses an. Man schilderte ausführlich die einzelnen Referate und stellte sie inhaltlich zusammen, und zwar nach den folgenden Stichpunkten: Leserschaft, Editionswesen, Informationsquellen über Bücher, Bibliotheken, Buchwissenschaft, Verlagsbewegung. Man bemerkte auch die grundlegenden Hypothesen und Forschungsthesen der Referenten. In Bezug auf die ausländischen Vorträge betonte man die darin vorhandenen Polonica. Man unterstrich die Geschicklichkeit des Organisators, der wegen der COVID-19-Pandemie dazu gezwungen war, die Tagung online zu organisieren. Er nutzte vollständig die Möglichkeiten, die diese Kommunikationsform anbietet, vor allem das Chat, dank dem das sofortige Kommentieren, Fragestellen und der Meinungsaustausch zwischen den Teilnehmern überhaupt möglich waren. Es ist auch zu betonen, dass die Tagung von einer internationalen Exlibris-Ausstellung begleitet war, die nach dem Stichwort „Institut für Wissenschaftliche Information und Bibliothekswissenschaft der Universität Wrocław (Breslau)“ betitelt war. 